\title{
Response of oxidative stress and inflammatory biomarkers to a 12-week aerobic exercise training in women with metabolic syndrome
}

\author{
Juliano Boufleur Farinha ${ }^{1,2^{*}}$, Flávia Mariel Steckling ${ }^{1}$, Sílvio Terra Stefanello ${ }^{3}$, Manuela Sangoi Cardoso ${ }^{4}$, \\ Larissa Santos Nunes ${ }^{5}$, Rômulo Pillon Barcelos ${ }^{3}$, Thiago Duarte ${ }^{3}$, Nélson Alexandre Kretzmann ${ }^{6}$, Carlos Bolli Mota ${ }^{1}$, \\ Guilherme Bresciani ${ }^{7}$, Rafael Noal Moresco ${ }^{4}$, Marta Maria Medeiros Frescura Duarte ${ }^{8}$, Daniela Lopes dos Santos ${ }^{1}$ \\ and Félix Alexandre Antunes Soares ${ }^{3}$
}

\begin{abstract}
Background: Evidences have been highlighted the relationship among metabolic syndrome, chronic low-grade inflammation, oxidative stress and several diseases. In this sense, the aim of this study was to investigate the effects of aerobic exercise training on oxidative stress and inflammatory parameters on women with metabolic syndrome (MS).

Methods: Twenty-three untrained women (51.86 \pm 6.58 years old, BMl $30.8 \pm 4.3 \mathrm{~kg} / \mathrm{m}^{2}$ ) completed a 12-week treadmill exercise training, without modifications on dietary pattern. Advanced oxidation protein products (AOPP), thiobarbituric acid-reactive substances (TBARS), total thiol content (T-SH) and nitrite and nitrate (NOx) levels were assessed in plasma while the levels of interleukin-1 beta (IL-1ß), interleukin-6 (IL-6), interleukin-10 (IL-10), tumor necrosis factor alpha (TNF-a) and interferon-gamma (IFN- $\gamma$ ) were evaluated in the serum. The RNA expression (mRNA) of IL-1 $\beta$, IL-10, TNF-a, IFN- $\gamma$, insulin receptor substrate 2 (IRS-2) and matrix metalloproteinase-9 (MMP-9) were performed inperipheral blood mononuclear cells (PBMC) of a subset with eight women with MS using real real-time polymerase chain reaction ( $\mathrm{PPCR}$ ).

Results: The intervention resulted in decreased serum levels of IL-1 $\beta, I L-6$, TNF- $a$, IFN- $\gamma$, AOPP and TBARS, besides increased levels of IL-10 and T-SH $(P<0.001)$. NOx concentrations were unchanged, similarly to mRNA expressions quantified in PBMC.

Conclusions: Twelve weeks of AT improved systemic oxidative stress and inflammatory biomarkers in women with MS, although PBMC mRNA expression for inflammatory pathways appeared to be unchanged. This may indicate that AT induced beneficial effects not only in physical fitness but also on health promotion through decreased oxidative damage and proinflammatory status.
\end{abstract}

\section{Key points}

- Moderate aerobic training improves serum/plasma oxidative stress and inflammatory biomarkers in women with metabolic syndrome, although mRNA expression in lymphocytes/monocytes does not change.

\footnotetext{
* Correspondence: jbfarinha@yahoo.com.br

1 Departamento de Métodos e Técnicas Desportivas, Universidade Federal de Santa Maria, Avenida Roraima 1000, Santa Maria 97105-900, Brazil

${ }^{2}$ Escola Superior de Educação Física, Universidade Federal do Rio Grande do Sul, Rua Felizardo 750, Porto Alegre 90690200, Brazil

Full list of author information is available at the end of the article
}

- One speculates that major weight loss afforded by exercise training is necessary to alter inflammatory gene expression levels in lymphocytes/monocytes, unlike inflammatory serum markers.

\section{Background}

The metabolic syndrome (MS) is characterized by interrelated risk factors such as impaired glucose tolerance, hypertriglyceridemia, low high-density lipoprotein (HDL) levels, raised blood pressure, and obesity (particularly visceral adiposity) [1]. During the last years, MS has 
consistently increased worldwide, becoming a public health concern and a clinical condition highly related to increasing obesity incidence, sedentary lifestyle, and excessive caloric intake [1].

Additionally, it has been shown that MS and obesity are linked with chronic low-grade systemic inflammation, particularly higher in women $[2,3]$. In this regard, persistent low-grade inflammation is described by a considerable increase in the systemic levels of cytokines, such as tumor necrosis factor alpha (TNF- $\alpha$ ), interleukin-1 beta (IL-1 $\beta$ ), and interleukin-6 (IL-6), which presence is highly related to atherosclerosis, non-alcoholic fatty liver disease, and type 2 diabetes mellitus (T2DM) [4-6]. The increased cytokine levels facilitate the intracellular influx of peripheral blood mononuclear cells (PBMC), which include lymphocytes and monocytes, constituting an important component of the immune system. In this sense, a synergistic relationship between low-grade systemic inflammation and oxidative stress has also been postulated. Regarding this, cytokines and immune cells are able to trigger the production of reactive oxygen (ROS) and nitrogen species (RNS) to cope with defense activities [3]. On the opposite, unbalanced cytokine release results in increased ROS production and oxidative stress-related conditions [3], such as atherosclerosis, stroke, renal and liver disorders, rheumatoid arthritis, auto-immune deficiencies, cancer, and Alzheimer's and Parkinson's diseases $[7,8]$. Therefore, evidence point out to an interaction among low-grade systemic inflammation with ROS overproduction, leading to these oxidative stress- and inflammation-related conditions previously mentioned.

It has been recently stated that aerobic exercise training (AT) may be considered as the most effective nonpharmacological tool for MS treatment [9]. However, despite several studies which demonstrated the antioxidant and anti-inflammatory effects of AT $[6,10,11]$, other trials do not present inflammatory and oxidative profiles after a short-duration moderate-intensity AT in T2DM and obese women [3,12]. Furthermore, studies involving messenger RNA (mRNA) inflammatory marker gene expression in PBMC have so far evaluated the acute effects of exercise or the outcomes of a diet program [13-16], while the consequences of an AT have not been reported yet in this population. Therefore, the aim of this study was to investigate the effects of a 12 -week moderateintensity aerobic training on inflammatory and oxidative stress parameters in middle-aged women with metabolic syndrome.

\section{Methods}

\section{Participants}

Through newspapers and institutional website advertisements, 30 untrained middle-aged women volunteered to participate in the study. Participants were selected based upon the following criteria: 1) at least two MS characteristics using the South American waist circumference cutpoints [1], 2) age between 40 and 64 years, and 3) a full medical screening with a sports science physician. Moreover, before the study onset, subjects were asked to not alter diet intake throughout the training schedule. The study was approved by the Ethics Committee of the Universidade Federal de Santa Maria (0032.0.243.00007) and followed the statements of the Declaration of Helsinki. All participants gave their informed consent after being fully informed about experimental procedures.

\section{Study design}

At baseline and after 12 weeks of AT, participants underwent a series of anthropometric measurements, cardiorespiratory fitness test, and resting heart rate (RHR) in order to assess anthropometric and functional profiles. Serum, plasma, and PBMC were used to evaluate biochemical, oxidative stress, and inflammatory status. To minimize a possible nutritional bias, participants were encouraged to maintain the habitual dietary intake during the study and filled in a 3-day diet record. During the sessions of exercise schedule, training intensity was controlled with heart rate monitors.

\section{Training protocol}

The AT was designed according to the recommendations of physical training for MS patients [17] (Table 1). The protocol consisted on treadmill brisk walking and/or slow jogging 3 days per week (48-h rest between sessions). In each day, the subjects were divided in six groups (three or four volunteers per class), where the patients were accompanied by two or three physical trainers per class, thus, affording almost a personal treatment for intensity accompaniment and constant motivation. We applied overloads in duration and/or intensity every 1 or 2 weeks

Table 1 Aerobic training schedule

\begin{tabular}{lll}
\hline Week & Duration $(\boldsymbol{m i n})$ & Intensity (\% of HRR) \\
\hline 1 & 30 & 50 \\
2 & 35 & 55 \\
$3-4$ & 40 & 55 \\
5 & 40 & 60 \\
$6-7$ & 45 & 60 \\
8 & 45 & 65 \\
$9-10$ & 50 & 65 \\
11 & 55 & 70 \\
12 & 60 & 70 \\
\hline
\end{tabular}

HRR, heart rate reserve. 
to promote several adaptations, taking into consideration that the patients were previously untrained and presented MS. The large variability of sessions' duration and intensity are explained by the need of gradual progression of volume and intensity loads [17]. Taking into account the risk of cardiovascular complications in middle-aged and older adults, this risk can be minimized by beginning a training schedule at light-to-moderate intensity, employing a gradual progression of the volume of the physical training, as stated by the principles of training [17]. The intensity was controlled across the target heart rate reserve (HRR) [18]. The training sessions started with a 5min warm-up performed on treadmills at approximately $40 \%$ HRR and ended up with a 5-min recovery and stretching. All training sessions were individually supervised, and the heart rate was continuously monitored using heart rate monitors (Polar RS 400, Polar Electro Oy, Kempele, Finland). The AT duration and intensity of the sessions ranged from 30 to $60 \mathrm{~min}$ and 50 to $65 \%$ of the HRR [17] during the 12 weeks of the training schedule.

\section{Resting heart rate, blood pressure, and cardiorespiratory fitness assessment}

The subject's RHR was measured during 5 min in supine position, and the lower value was registered by a heart rate monitor (Polar RS 400, Polar Electro Oy, Kempele, Finland). After, resting systolic and diastolic pressures were measured after participants sat quietly in a padded chair for $5 \mathrm{~min}$ with a digital sphygmomanometer (Omron, Kyoto, Japan). The cardiorespiratory fitness was assessed by a graded treadmill test (ATL-10.100, Inbramed, Porto Alegre, Brazil) according to the Bruce's modified protocol [19], and the maximal oxygen uptake $\left(\mathrm{VO}_{2} \mathrm{max}\right)$ was calculated as previously described [17]. Participants were verbally encouraged to perform the maximum effort during the test. In this submaximal test, the $\mathrm{VO}_{2}$ max was achieved by attaining heart rate over $85 \%$ of age-predicted maximum and volitional fatigue according to previous recommendations [17].

\section{Anthropometry}

Subjects were weighed with a scale (Plenna, São Paulo, Brazil) and height measured with a stadiometer (Cardiomed, Curitiba, Brazil). The waist-hip ratio was determined by measuring waist circumference at the narrowest region between the costal margin and iliac crest and dividing by the hip circumference measured at its greatest gluteal protuberance by a spring-loaded metal tape. The body lean mass, body fat mass, trunk fat mass, arm fat mass, and leg fat mass were determined using dual-energy X-ray absorptiometry (DXA) with a densitometer machine (Hologic Discovery QDR, Bedford, USA). Briefly, after a 12-h fasting and $24 \mathrm{~h}$ without exercising, participants wore only a light coat, lay on the DXA table in supine position with arms adequately separated from the trunk and were asked to remain still throughout the scanning procedure.

\section{Blood collection and preparation}

Blood samples were drawn from the vein of the antecubital region following a 12-h fasting, and participants were asked to avoid intense physical exercise $72 \mathrm{~h}$ before sampling. All blood samples were drawn into 4-mL EDTA anticoagulant or serum separator tubes. Serum and plasma were routinely centrifuged at $1,500 \times g$ for $15 \mathrm{~min}$. Plasma and serum were stored at $-80^{\circ} \mathrm{C}$ for subsequent analysis. PBMC were immediately separated from anticoagulated peripheral blood by density gradient centrifugation with Histopaque-1077 solution (SigmaAldrich, St. Louis, USA), as previously described [16], and with short modifications. For each sample, four $15-\mathrm{mL}$ centrifuge tubes were used to layer $7 \mathrm{~mL}$ of blood and phosphate-buffered saline (PBS) $(136 \mathrm{mM} \mathrm{NaCl}$, $2.7 \mathrm{mM} \mathrm{KCl}, 7.8 \mathrm{mM} \mathrm{Na}_{2} \mathrm{HPO}_{4}, 1.7 \mathrm{mM} \mathrm{KH}_{2} \mathrm{PO}_{4}$ ) onto $3 \mathrm{~mL}$ of Histopaque ${ }^{\circ}-1077$. The suspension was centrifuged for $40 \mathrm{~min}$ at $275 \times \mathrm{g}$ at room temperature. After, the mononuclear cell layer was removed with manual pipetting and washed in PBS. Then, cell supernatants were discarded, and the PBMC pellets were dried out with lysing solution $\left(150 \mathrm{mM} \mathrm{NH} \mathrm{ml}_{4} \mathrm{Cl}, 10 \mathrm{mM} \mathrm{NaHCO}, 1 \mathrm{mM}\right.$ EDTA) and centrifuged for $3 \mathrm{~min}$ at $300 \times g$. Finally, samples were stored with RNAlater (Sigma-Aldrich, St. Louis, USA) and frozen at $-80^{\circ} \mathrm{C}$ for further analysis.

\section{Serum biochemical assays}

Total cholesterol and HDL were determined using commercially available assay kits (Bioclin, Belo Horizonte, Brazil) on a Cobas MIRA automated analyzer (Roche Diagnostics, Basel, Switzerland). Serum triglycerides (TG) and glucose were determined using commercial kits (Bio Técnica, Varginha, Brazil). The cytokine levels were determined by enzyme-linked immunosorbent assay (ELISA) using commercial kits for human IL-1 $\beta$, IL-6, interleukin10 (IL-10), TNF- $\alpha$, and interferon-gamma (IFN- $\gamma$ ), according to manufacturer's instructions (eBIOSCIENCE, San Diego, USA). The IL-1 $\beta$, IL-6, and IL-10 kits were sensitive to $2 \mathrm{pg} / \mathrm{mL}$. TNF- $\alpha$ and IFN- $\gamma$ kits presented sensitivities of $4 \mathrm{pg} / \mathrm{mL}$ and $4 \mu \mathrm{g} / \mathrm{mL}$, respectively.

\section{Plasma assays}

Oxidative damage to proteins was measured by advanced oxidation protein products (AOPP) as previously described [20]. Shortly, plasma and chloramine-T calibration standards were transferred to test tubes. Potassium iodide (KI) (Sigma-Aldrich, St. Louis, USA) was added to the standards, and citric acid was added to the 
plasma samples. After 2 min on a tube shaker, the absorbance was read at $340 \mathrm{~nm}$ against a solvent blank (citric acid and KI). AOPP concentrations are expressed as micromole per liter of chloramine-T equivalents, abbreviated to $\mu \mathrm{mol} / \mathrm{L}$ in this article. As an index of lipoperoxidation, thiobarbituric acid-reactive substances (TBARS) were assayed as previously described [21]. TBARS consists in an acid-heating reaction of the lipid peroxidation end product, malondialdehyde (MDA), with thiobarbituric acid (TBA). TBARS were determined spectrophotometrically at $532 \mathrm{~nm}$ and expressed as microgram per deciliter of MDA.

Nitrite and nitrate (NOx) levels were assessed by a modified Griess method. Briefly, samples were pippeted into the reaction cuvette, and vanadium (III) chloride $\left(\mathrm{VCl}_{3}\right)$ (Sigma-Aldrich, St. Louis, USA) was added to reduce nitrate to nitrite after $25 \mathrm{~s}$. Thus, Griess reagent (Sigma-Aldrich, St. Louis, USA) was added, and the resultant mixture was incubated for $20 \mathrm{~min}$ and read at $550 \mathrm{~nm}$ [22]. Creatinine content was determined using a commercially available assay kit (Labtest, Lagoa Santa, Brazil). Plasma levels of AOPP, creatinine, and NOx were measured on an automated analyzer Cobas MIRA ${ }^{\bullet}$ (Roche Diagnostics, Basel, Switzerland). Moreover, total thiol group concentrations (T-SH) were assessed by reacting with [5,5'-dithiobis(2-nitrobenzoic acid); DTNB] [23], read at $412 \mathrm{~nm}$, and expressed in nanomole per milligram of glutathione (GSH).

\section{PBMC gene mRNA expression}

Total RNA was isolated from PBMC using RiboPure ${ }^{\mathrm{Tu}}$ Blood Kit (Ambion Inc., Austin, USA) and quantified by the fluorescent method Ribogreen RNA Quantification Kit (Molecular Probes, Leiden, The Netherlands), as previously described [16]. The integrity of the RNA was assessed using agarose gel electrophoresis. RNA was reverse-transcribed using random hexamer primers. Realtime polymerase chain reaction (qPCR) was performed using SYBR Green I reagent (Applied Biosystems, Foster City, USA) with Mx3000P real-time PCR Stratagene (GE) system. Data was processed by the fully integrated MX PRO software. Relative changes in gene expression levels were determined using the $2^{-\Delta \Delta \mathrm{ct}}$ method as described previously [24]. Shortly, this method requires the assignment of one housekeeping gene ( $\beta$-actin in this case), which is assumed to be constantly expressed in all samples. Then, the expression of other samples is compared to that in reference sample. TaqMan primers and probes for IL-1 $\beta$, IL10 , TNF- $\alpha$, IFN- $\gamma$, insulin receptor substrate 2 (IRS-2), matrix metalloproteinase-9 (MMP-9), and $\beta$-actin (Table 2) were designed from the commercially available TaqMan ${ }^{\circ}$ Assays-on-Demand Gene (Invitrogen, Carlsbad, USA). Considering the dual role of interleukin-6 (IL-6) as a proinflammatory and sometimes anti-inflammatory (pleiotropic effects) mediator according to the tissue (cell-specific actions) $[6,14]$, we have decided to rule it out and focus on well-established proinflammatory or anti-inflammatory markers. Regarding questions concerning available funds, the researchers analyzed the patients which more responded to the training (higher deltas) in relation to serum cytokine levels and utilized the PBMC samples previously stored for these eight patients to perform qPCR assays. Measurements were performed at baseline and at the end of the study, with samples analyzed in duplicate.

\section{Dietary intake assessment}

In order to determine total daily caloric and macronutrient intake, participants were instructed to self-report the exact amount of food and drink consumed over two weekdays and one weekend day in a 3-day diet record. Energy intake was determined using a dietary analysis software (Avanutri Revolution, Rio de Janeiro, Brazil).

\section{Statistical analysis}

The Shapiro-Wilk test was carried out to assess the normality of variable distribution. According the normality of data, paired Student's $t$ test and Wilcoxon signed rank test were utilized to determine differences pre and post training. PBMC parameters were compared by Student's $t$ test for independent samples or by the Mann-Whitney U test. Statistical Package for Social Sciences (SPSS 15.0, Chicago, USA) was used, and statistical significance set at $P<0.05$. Data were expressed as mean \pm standard deviation of mean $(\mathrm{SD})$.

\section{Results}

\section{Sample characterization}

From the initial sample, 23 participants (18 postmenopausal and 5 participants with regular menses) aging $51.86 \pm 6.58$ years old and presenting $158 \mathrm{~cm}$ of height completed the training schedule and were considered in the statistical analysis. There were no significant differences between postmenopausal women and those with regular menses on biochemical, oxidative stress, and inflammatory blood parameters before and/or after AT (data not shown). None of the participants used any form of hormone replacement therapy. From the initial sample, three patients dropped out due to health problems unrelated to the study and five for private reasons. Overall, $82.61 \%(n=19)$ of the participants presented three or more MS characteristics at baseline, and the adherence to the exercise training was $84.65 \%$ (number of sessions attended $\times 100 /$ number of sessions offered) throughout the study. 
Table 2 Primers used in qPCR

\begin{tabular}{|c|c|c|c|c|c|c|}
\hline Gene & $\begin{array}{l}\text { Sense } \\
\text { primers }\left(5^{\prime} \rightarrow 3^{\prime}\right)\end{array}$ & $\begin{array}{l}\text { Anti-sense } \\
\text { primers }\left(5^{\prime} \rightarrow 3^{\prime}\right)\end{array}$ & $\begin{array}{l}\text { Fragment } \\
\text { length (bp) }\end{array}$ & $\begin{array}{l}\text { Annealing } \\
\text { temperature }\left({ }^{\circ} \mathrm{C}\right)\end{array}$ & $\begin{array}{l}\text { Mean } \\
\text { Ct BT }\end{array}$ & $\begin{array}{l}\text { Mean } \\
\text { Ct AT }\end{array}$ \\
\hline $\mathrm{IL}-1 \beta$ & ATGATGGCTTATTACAGTGGCAA & GTCGGAGATTCGTAGCTGGA & 132 & 57 & 38.9 & 37.7 \\
\hline $\mid \mathrm{IL}-10$ & GACTITAAGGGTTACCTGGGTTG & TCACATGCGCCTTGATGTCG & 112 & 58 & 34.1 & 36.6 \\
\hline TNF-a & GAGGCCAAGCCCTGGTATG & CGGGCCGATTGATCTCAGC & 91 & 57 & 37.6 & 37.7 \\
\hline $\mathrm{IFN}-\gamma$ & TCGGTAACTGACTTGAATGTCCA & TCGCTTCCCTGTITTAGCTGC & 93 & 57 & 31.9 & 34 \\
\hline IRS-2 & CCCGACTTCTTCTCCGCAG & GAAGGCACTACAGGGTGAGG & 124 & 58 & 35.1 & 35.3 \\
\hline MMP-9 & TGGGCTACGTGACCTATGACAT & GCCCAGCCCACCTCCACTCCTC & 128 & 54 & 32.2 & 34.9 \\
\hline$\beta$-actin & GCTTCTTTGCAGCTCCTTCGT & ATATCGTCATCCATGGCGAAC & 150 & 56 & 32.6 & 35.6 \\
\hline
\end{tabular}

$\mathrm{Ct}$, threshold cycle; $\mathrm{BT}$, before training; $\mathrm{AT}$, after training.

\section{Changes in anthropometric, functional, and biochemical serum parameters}

The AT did not alter the hip circumference, RHR, and systolic and diastolic blood pressure values. However, the participants exhibited a significant decrease in body weight $(P<0.001)$, body mass index (BMI) $(P<0.001)$, waist circumference $(P<0.001)$, waist-hip ratio $(P=$ $0.004)$, total body fat mass $(P<0.001)$, truncal fat mass $(P<0.001)$, arm fat mass $(P=0.015)$, leg fat mass $(P<0.001)$ and an increase in total body lean mass $(P=0.03) \quad$ (Table 3$)$. With regard to cardiorespiratory fitness, participants showed a greater $\mathrm{VO}_{2} \mathrm{max}$ levels $(P<0.001)$ and a longer time spent in the test $(P<0.001)$ after the training. Although glucose, total cholesterol, TG, and HDL levels were unchanged, creatinine concentration decreased after the intervention $(P=0.017)$ (Table 3).

\section{Energy intake characteristics}

No differences were observed in total caloric intake and amount of carbohydrate, protein, and lipid consumed during the AT (Table 4).

\section{Oxidative stress markers}

The levels of TBARS $(P<0.05)$ and AOPP $(P<0.001)$ decreased in women with MS after the AT protocol. Furthermore, an increase in T-SH levels $(P<0.001)$ was observed while the NOx levels were unchanged $(P=0.191)$ after the AT (Table 5).

\section{Cytokine concentrations}

Twelve weeks of moderate-intensity AT resulted in a great effect on systemic cytokine levels (Figure 1). The serum levels of proinflammatory IL-1 $\beta(P<0.001)$ (Figure 1a), IL-6 $(P<0.001)$ (Figure 1b), INF- $\gamma(P<0.001)$ (Figure 1c), and TNF- $\alpha(P<0.001)$ (Figure 1d) decreased after the AT in women with MS. Besides, the concentration of the antiinflammatory cytokine IL-10 $(P<0.001)$ was higher after the AT (Figure 1e).

\section{Changes in gene expression in PBMC}

IL-1 $\beta$, TNF- $\alpha$, IFN- $\gamma$, IL-10, IRS-2, and MMP-9 mRNA expression in PBMC of a subset with eight women with MS was unchanged along the intervention (Figure 2).

\section{Discussion}

The main findings of this study are that 12-week moderate-intensity aerobic training decreases oxidative stress and inflammatory parameters in women with metabolic syndrome, despite no changes in PBMC mRNA

Table 3 Anthropometric, biochemical, and functional characteristics of the participants before and after the training protocol $(n=23)$

\begin{tabular}{|c|c|c|}
\hline Parameter & Before & After \\
\hline Body weight (kg) & $76.9 \pm 11.8$ & $75.6 \pm 12.3^{* *}$ \\
\hline $\mathrm{BMI}\left(\mathrm{kg} / \mathrm{m}^{2}\right)$ & $30.8 \pm 4.3$ & $30.2 \pm 4.5^{* *}$ \\
\hline Waist circumference $(\mathrm{cm})$ & $93.4 \pm 10.63$ & $91.5 \pm 10.7^{* *}$ \\
\hline Hip circumference $(\mathrm{cm})$ & $106 \pm 8.5$ & $105.2 \pm 8.6$ \\
\hline Waist-hip ratio & $0.87 \pm 0.05$ & $0.86 \pm 0.06^{*}$ \\
\hline Total body lean mass (kg) & $39.2 \pm 5.3$ & $39.6 \pm 5.5^{*}$ \\
\hline Total body fat mass (kg) & $33.7 \pm 7.2$ & $32.3 \pm 7^{* *}$ \\
\hline Truncal fat mass (kg) & $17.9 \pm 4.5$ & $16.8 \pm 4.5^{* *}$ \\
\hline Arms fat mass $(\mathrm{kg})$ & $4 \pm 0.9$ & $3.8 \pm 0.9^{*}$ \\
\hline Legs fat mass (kg) & $11 \pm 2.63$ & $10.6 \pm 2.63^{* *}$ \\
\hline Resting heart rate (bpm) & $66 \pm 8.5$ & $67.2 \pm 9.8$ \\
\hline Systolic blood pressure $(\mathrm{mmHg})$ & $123.4 \pm 15.7$ & $120.7 \pm 14.8$ \\
\hline Diastolic blood pressure (mmHg) & $76.8 \pm 11$ & $75.6 \pm 11.3$ \\
\hline $\mathrm{VO}_{2} \max \left(\mathrm{ml} \cdot \mathrm{kg}^{-1} \cdot \mathrm{min}^{-1}\right)$ & $32.1 \pm 5.9$ & $36.9 \pm 5.6^{* *}$ \\
\hline Total exercise test duration (min) & $15.6 \pm 2$ & $17.3 \pm 1.9^{* *}$ \\
\hline Glucose (mg/dL) & $110 \pm 34.6$ & $103.8 \pm 26.3$ \\
\hline Total cholesterol (mg/dL) & $188.1 \pm 46.3$ & $204.4 \pm 39.2$ \\
\hline Triglycerides (mg/dL) & $162.1 \pm 108.6$ & $124.1 \pm 53.2$ \\
\hline $\mathrm{HDL}(\mathrm{mg} / \mathrm{dL})$ & $34.1 \pm 13.5$ & $36.9 \pm 7.8$ \\
\hline Creatinine $(\mathrm{mg} / \mathrm{dL})$ & $0.73 \pm 0.1$ & $0.67 \pm 0.1$ \\
\hline
\end{tabular}

BMI, body mass index; $\mathrm{VO}_{2}$ max, maximal oxygen uptake; $\mathrm{HDL}$, high-density lipoprotein.

${ }^{*} P<0.05$ and ${ }^{* *} P<0.001$ after vs. before training. 
Table 4 Energy intake before and after the training protocol $(n=23)$

\begin{tabular}{lll}
\hline Variables & Before & After \\
\hline Energy intake (kcal) & $1,469.5 \pm 394.1$ & $1,379.3 \pm 415.2$ \\
Carbohydrate (kcal) & $801.9 \pm 280.1$ & $739.9 \pm 263.7$ \\
Protein (kcal) & $283.9 \pm 127.8$ & $261.7 \pm 109.4$ \\
Lipid (kcal) & $367.9 \pm 163.3$ & $378.6 \pm 170.1$ \\
\hline
\end{tabular}

Values are expressed as mean \pm SD.

expression being observed. To our knowledge, this is the first study to investigate the effects of a moderateintensity AT on PBMC mRNA expression of inflammatory and glucose metabolism genes using $\mathrm{qPCR}$. It may also be assumed that the intensity and duration of the AT sessions were sufficient to induce metabolic and functional adaptations, considering that $\mathrm{VO}_{2}$ max and duration of treadmill exercise test were increased. Moreover, it is noteworthy that despite the absence of changes in some MS criteria classification (such as TG, HDL, and blood pressure levels), 12 weeks of moderate-intensity AT led to improvements in the oxidative metabolism and inflammation profiles in this population. Despite no significant changes in total energy, carbohydrate, protein, and lipid intake observed in participants along the protocol, the low mean self-reported intake in a 3 -day diet record $(\sim 1,430 \mathrm{kcal})$ should be linked to the recognized great underreporting in obese participants [25].

The AT here described induced total body and truncal fat mass decreases and body lean mass increases in MS women. Changes in total body and truncal fat are likely connected with the decreased cytokine concentrations, considering hypertrophied adipocytes are responsible for the cytokine release on obesity [5]. In this regard, the adipose tissue is considered not only such a fat depot but also an endocrine tissue linked to appetite modulation, insulin sensitivity, endocrine and reproductive systems, bone metabolism, inflammation, and immunity [26]. In fact, AT increases energy expenditure and conducts lipolysis of both subcutaneous and intramuscular fat stores [27] accumulated in individuals who ingest

Table 5 Oxidative stress plasma parameters before and after the training protocol $(n=23)$

\begin{tabular}{lll}
\hline Parameter & Before & After \\
\hline AOPP $(\mu \mathrm{mol} / \mathrm{L})$ & $100.4 \pm 34.5$ & $69 \pm 17.9^{* *}$ \\
$\mathrm{NOx}(\mu \mathrm{mol} / \mathrm{L})$ & $65.3 \pm 40.7$ & $53 \pm 6.96$ \\
TBARS $(\mu \mathrm{g} / \mathrm{dL}$ of MDA) & $29.1 \pm 10.5$ & $24.3 \pm 9.3^{*}$ \\
T-SH $(\mathrm{nmol} / \mathrm{mg}$ of GSH) & $51.8 \pm 12$ & $69 \pm 14.3^{* *}$
\end{tabular}

AOPP, advanced oxidation protein products; NOx, nitrite and nitrate; TBARS, thiobarbituric acid-reactive substances; MDA, malondialdehyde; T-SH, total thiol content; GSH, glutathione.

${ }^{*} P<0.05$ and ${ }^{* *} P<0.001$ after vs. before training. more energy than they need [28], such is the case of MS patients.

Elevated white adipose tissue, hyperglycemia, endothelial ROS production, and inadequate antioxidant defenses are connected to oxidative stress in obesity [8]. In the current study, the AT induced a decrease on oxidative damage (TBARS and AOPP) with a concomitant increase in antioxidant status (T-SH) in MS women, indicating oxidative balance. The long-term exercise-induced adaptations of oxidative stress are similar to the general principles of exercise training [11]. This suggests that the chronic exposure to prooxidant agents such as bouts of moderate aerobic exercises results in the upregulation of antioxidant defenses, providing a balance between the ROS-induced damage and the antioxidant systems [3,11]. At same time, the adipose tissue expression of $\mathrm{NADPH}$ oxidase, an important source of ROS production, was found downregulated by AT in rodents, with more remarkable effects in visceral than in subcutaneous white adipose tissue [29]. In conjunction, these factors led to oxidative damage repair, decreasing the risk of chronic diseases.

Nitrite and nitrate are products of nitric oxide (NO) and were unchanged in this study. The NO presents a dual physiological role, considering its beneficial and potent vasodilator function and its detrimental oxidative damage through peroxynitrite $\left(\mathrm{ONOO}^{*-}\right)$ formation [30], reducing the bioavailability of $\mathrm{NO}$ for vasodilator, antihypertensive, and antiatherosclerotic effects. While a study involving a 12-week AT with elderly women found increased plasma levels of NOx [31], another encompassing 16-week AT with women at risk for hypertension showed no differences on this marker [32]. Moreover, it is likely that the lack of checking of the intake of food sources of NOx over $24 \mathrm{~h}$ prior to blood collections in our study had limited the comparison of this finding [31]. Another hypothesis is that exercise training induces the enlargement of conduit vessels, leading to the normalization of shear stress and decreased activation of endothelial nitric oxide synthase [33], probably linked to decreased plasma NO products.

This study found that a 12-week moderate-intensity AT reduced IL-1 $\beta$, IL-6, TNF- $\alpha$, and INF- $\gamma$ serum levels, while IL-10 was increased. Some mechanisms have been proposed to explain how exercise training may reduce chronic low-grade inflammation in MS. It is known that as well as the adipose tissue, the working skeletal muscle is a potential source of cytokines. The IL- 6 produced by myocytes through of AMP-activated protein kinase (AMPK) activation at sufficient AT intensities presents anti-inflammatory effects as opposed to IL-6 secreted by adipose tissue, promoting the release of IL-10 and interleukin-1 receptor antagonist (IL-1RA), with a concomitant inhibition of TNF- $\alpha$ production during the 

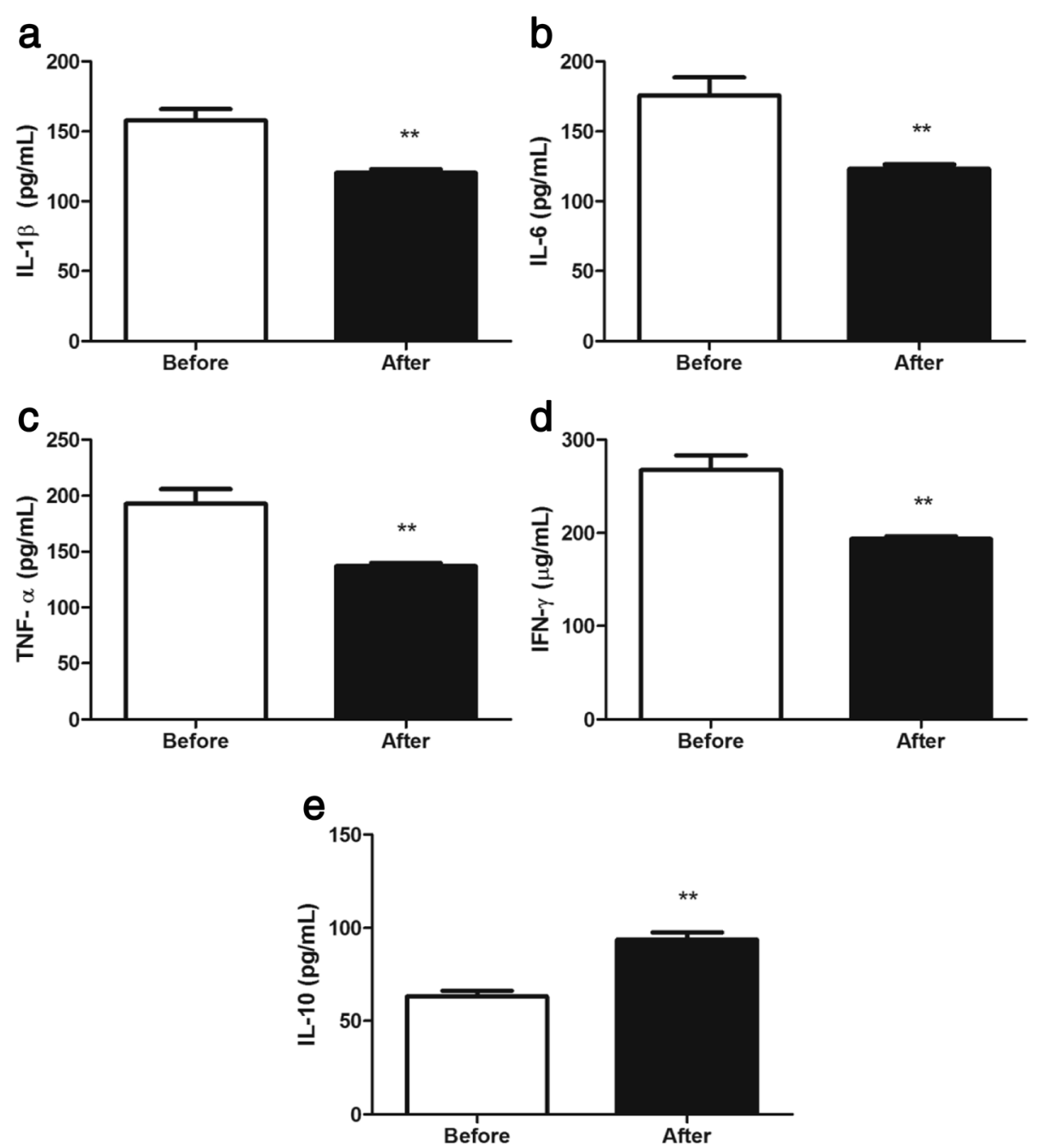

Figure 1 Effects on systemic cytokine levels. Aerobic training effects on interleukin-1 beta (IL-1 $\beta$ ) (a), tumor necrosis factor alpha (TNF-a) (b), interleukin-6 (IL-6) (c), interferon-gamma (INF- $\gamma)$ (d), and interleukin-10 (IL-10) (e) levels. Data are expressed as means \pm standard error of the mean. ${ }^{*} P<0.05$ and ${ }^{* *} P<0.001$ after vs. before training.

effort and some hours after the exercise sessions [6]. Another possible mechanism is the reduced expression of the toll-like receptors and nuclear transcription factor $\kappa \mathrm{B}(\mathrm{NF} \mathrm{B})$ on monocytes and macrophages, probably linked to hormonal and heat shock protein levels, increased lipolysis, and reduced number of monocytes reported in some studies [5,28]. Moreover, recent evidences show that exercise training may increase angiogenesis and blood supply, thereby reducing hypoxia and the associated inflammation in adipose tissue [5]. Exercise training may also improve the capacity to regenerate endothelial cell after injury, increase laminar shear stress, and reduce the release of adhesion molecules, downregulating the leukocyte migration into the vessel wall and reducing local inflammation [5]. In summary, the mechanisms concerning lower systemic inflammation afforded by AT contribute to health achievement/improvement, represented by the protection against cardiovascular diseases among others [6] in MS women.

It is known that monocytes generate superoxide $\left(\mathrm{O}_{2}^{*}\right)$, hydrogen peroxide $\left(\mathrm{H}_{2} \mathrm{O}_{2}\right)$, hydroxyl radical $\left(\mathrm{OH}^{*}\right)$, and $\mathrm{ONOO}^{*-}$ and macrophages produce cytokines [8]. This leads to a repeated cycle of adipocyteinitiated macrophage recruitment and cytokine/ROS production by monocytes/macrophages [8]. In fact, PBMC are the primary cytokine secretors, and the infiltration/differentiation of these cells into macrophages in fat depots and/or endothelium represents a key role in the development of persistent tissue inflammation and atherosclerotic lesions $[8,28,34]$. Given the difficulties of hepatic, muscle, and adiposeassociated immune cell collection, studies with PBMC 

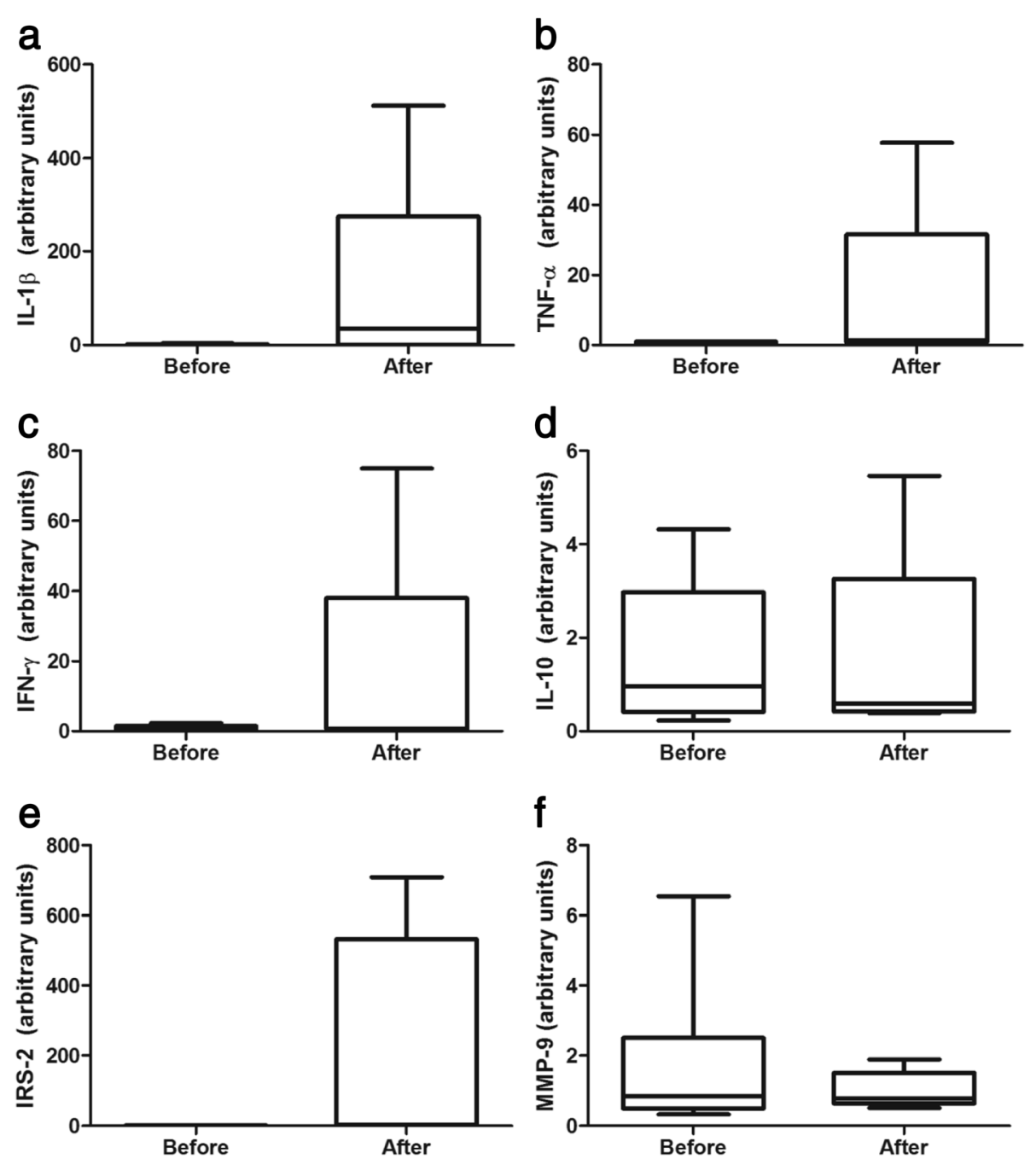

Figure 2 IL-1 $\beta$, TNF- $a$, IFN- $\gamma$, IL-10, IRS-2, and MMP-9 mRNA expression in PBMC. Box plots of aerobic training effects on interleukin-1 beta $(\mathrm{IL}-1 \beta)(\mathbf{a})$, tumor necrosis factor alpha (TNF-a) (b), interferon-gamma (IFN)- $\gamma(\mathbf{c})$, interleukin-10 (IL-10) (d), insulin receptor substrate 2 (IRS-2) (e), and matrix metalloproteinase-9 (MMP-9) (f) mRNA expression in PBMC of eight women with metabolic syndrome. Values are normalized to $\beta$-actin mRNA expression. Data are expressed as median, interquartile range, and whiskers extending to the 5 th and 95 th percentiles. ${ }^{*} P<0.05$ and ${ }^{* *} P<0.001$ after vs. before training.

may clarify mechanisms of immune dysfunction in MS. Concerning AT, evidences hypothesize that it may cause repeated short-lasting elevations in circulating levels of chemokines which downregulate the expression of their receptors on PBMC and restrict migration of these cells towards adipose tissue [28].

Previous studies concerning serum or plasma cytokine levels and their concentrations and/or mRNA expression in PBMC have evaluated the acute effects of exercise $[13,16]$, the outcomes of a diet program [14], or the impact of caloric restriction combined with physical activity advising [15]. To our knowledge, this is the first study to investigate the effects of chronic exercise on inflammatory gene expression in PBMC. This study shows that a 12-week moderate-intensity AT may not change
IL- $1 \beta$, TNF- $\alpha$, IFN- $\gamma$, IL-10, IRS-2, and MMP-9 mRNA expression levels in PBMC of MS women. However, it is important to mention that a reduced amount of PBMC samples was assayed, and thus this data interpretation must be taken carefully. Previous studies demonstrated that a 33-week caloric restriction in obese individuals with MS did not change IL-10 mRNA expression, while it decreased IL- $1 \beta$, IL-1RA, TNF- $\alpha$, and its receptors mRNA levels $[14,35]$. On the same line, a trial encompassing 12-week diet and regular walking advising, but not controlled, showed decreased mRNA expression for TNF- $\alpha$ and MMP-9 in obese women [15]. In common, these interventions provoked approximately $4.8 \%$ of weight loss $[14,15,35]$, contrasting with our findings $(\sim 1.7 \%)$. Despite the statistical significance of body weight reduction 
found in our study, this decrease is not clinically relevant. Based on the aforementioned studies' findings [14,15,35], it could be hypothesized that major weight loss connected to exercise training is necessary to modulate inflammatory gene expression levels in PBMC. Moreover, it is noteworthy that although inflammatory gene expression in PBMC could reflect the production by these cells, it is not elucidated how it would interfere in the serum levels, considering mRNA expression do not directly reflect protein production and secretion [14,35]. It is also highlighted that the sample analyzed in this study presented a high standard deviation of mean in parameters regarding mRNA expression in PBMC. In this line, a more homogenous population could have led to different results in these variables.

\section{Conclusions}

In conclusion, here, we describe that a 12-week moderateintensity aerobic training induces positive effects on the oxidative stress and inflammatory modulation in women with metabolic syndrome. However, this AT does not appear to change mRNA expression of inflammatory and glucose metabolism parameters in PBMC. Moreover, despite study limitations such as the absence of a control group, cytokine protein expression, small sample considered for mRNA expression analysis, and the lack of control for the effect of estrogen in women with regular menstrual cycle, this study may serve as a basis to further randomize researches aimed at evaluating the effects of different exercise training programs on inflammatory parameters in immune cells of risk population. Furthermore, the effects of the same biomarkers after a period of detraining require clarification.

\section{Competing interests}

Juliano Boufleur Farinha, Flávia Mariel Steckling, Sílvio Terra Stefanello, Manuela Sangoi Cardoso, Larissa Santos Nunes, Rômulo Pillon Barcelos, Thiago Duarte, Nélson Alexandre Kretzmann, Carlos Bolli Mota, Guilherme Bresciani, Rafael Noal Moresco, Marta Maria Medeiros Frescura Duarte, Daniela Lopes dos Santos, and Félix Alexandre Antunes Soares declare that they have no conflict of interest.

\section{Authors' contributions}

Conceived the study: JBF, FAAS, DLS, GB, CBM. Performed the experiments: JBF, FMS, STS, MSC, LSN, RPB, TD, NAK, MMMFD. Analyzed the data: JBF, FAAS, DLS, RNM, GB. Wrote and/or revised the paper: JBF, GB, FAAS. All authors read and approved the final manuscript.

\footnotetext{
Acknowledgements

We greatly thank the Clínica Osteolab (Instituto de Densitometria Óssea) and ProximusTecnologia ${ }^{\circ}$ for the technical support and research incentive. Juliano Boufleur Farinha, Guilherme Bresciani, Sílvio Terra Stefanello, Rômulo Pillon Barcelos, Manuela Sangoi Cardoso, and Rafael Noal Mores coreceived fellowship by CAPES (Coordenação de Aperfeiçoamento de Pessoal de Nível Superior). Félix Alexandre Antunes Soares received a fellowship by CNPq (Conselho Nacional de Desenvolvimento Científico e Tecnológico). Additional financial support was given by FAPERGS/CNPq - PRONEM \#11/2029-1 (Programa de Apoio a Núcleos Emergentes).
}

\section{Author details}

'Departamento de Métodos e Técnicas Desportivas, Universidade Federal de Santa Maria, Avenida Roraima 1000, Santa Maria 97105-900, Brazil. ${ }^{2}$ Escola Superior de Educação Física, Universidade Federal do Rio Grande do Sul, Rua Felizardo 750, Porto Alegre 90690200, Brazil. ${ }^{3}$ Departamento de Bioquímica e Biologia Molecular, Universidade Federal de Santa Maria, Avenida Roraima 1000, Santa Maria 97105-900, Brazil. ${ }^{4}$ Departamento de Análises Clínicas e Toxicológicas, Universidade Federal de Santa Maria, Avenida Roraima 1000, Santa Maria 97105-900, Brazil. ${ }^{5}$ Centro Universitário Franciscano, Rua dos Andradas 1614, Santa Maria 97010-032, Brazil. ${ }^{6}$ Hospital de Clínicas de Porto Alegre, Rua Ramiro Barcelos 2350, Porto Alegre 90035-903, Brazil. ${ }^{7}$ Facultad de Ciencias de la Salud, Universidade Autónoma de Chile, Avenida Alemania 01090, Temuco 4810101, Chile. ${ }^{8}$ Universidade Luterana do Brasil, BR 287 km 252, Santa Maria 97020-001, Brazil.

Received: 4 September 2014 Accepted: 10 February 2015 Published online: 08 April 2015

\section{References}

1. Alberti KG, Eckel RH, Grundy SM, Zimmet PZ, Cleeman II, Donato KA, et al. Harmonizing the metabolic syndrome: a joint interim statement of the International Diabetes Federation Task Force on Epidemiology and Prevention; National Heart, Lung, and Blood Institute; American Heart Association; World Heart Federation; International Atherosclerosis Society; and International Association for the Study of Obesity. Circulation. 2009;120(16):1640-5.

2. Rogowski O, Shapira I, Berliner S. Exploring the usefulness of inflammationsensitive biomarkers to reveal potential sex differences in relation to low-grade inflammation in individuals with the metabolic syndrome. Metabolism. 2008;57(9):1221-6.

3. Devries MC, Hamadeh MJ, Glover AW, Raha S, Samjoo IA, Tarnopolsky MA. Endurance training without weight loss lowers systemic, but not muscle, oxidative stress with no effect on inflammation in lean and obese women. Free Radic Biol Med. 2008;45(4):503-11.

4. Esser N, Legrand-Poels S, Piette J, Scheen AJ, Paquot N. Inflammation as a link between obesity, metabolic syndrome and type 2 diabetes. Diabetes Res Clin Pract. 2014;13(14):00187-9.

5. You T, Arsenis NC, Disanzo BL, Lamonte MJ. Effects of exercise training on chronic inflammation in obesity: current evidence and potential mechanisms. Sports Med. 2013;43(4):243-56.

6. Petersen AM, Pedersen BK. The anti-inflammatory effect of exercise. J Appl Physio. 1985;98(4):1154-62.

7. Carocho M, Ferreira IC. A review on antioxidants, prooxidants and related controversy: natural and synthetic compounds, screening and analysis methodologies and future perspectives. Food Chem Toxicol. 2013;51:15-25.

8. Vincent HK, Taylor AG. Biomarkers and potential mechanisms of obesityinduced oxidant stress in humans. Int J Obes (Lond). 2006;30(3):400-18.

9. Otani H. Oxidative stress as pathogenesis of cardiovascular risk associated with metabolic syndrome. Antioxid Redox Signal. 2011;15(7):1911-26.

10. Karolkiewicz J, Michalak E, Pospieszna B, Deskur-Smielecka E, Nowak A, Pilaczynska-Szczesniak L. Response of oxidative stress markers and antioxidant parameters to an 8-week aerobic physical activity program in healthy, postmenopausal women. Arch Gerontol Geriatr. 2009;49(1):e67-71.

11. de Oliveira VN, Bessa A, Jorge ML, Oliveira RJ, de Mello MT, De Agostini GG, et al. The effect of different training programs on antioxidant status, oxidative stress, and metabolic control in type 2 diabetes. Appl Physiol Nutr Metab. 2012;37(2):334-44.

12. Giannopoulou I, Fernhall B, Carhart R, Weinstock RS, Baynard T, Figueroa A, et al. Effects of diet and/or exercise on the adipocytokine and inflammatory cytokine levels of postmenopausal women with type 2 diabetes. Metabolism. 2005;54(7):866-75.

13. Moldoveanu Al, Shephard RJ, Shek PN. Exercise elevates plasma levels but not gene expression of IL-1 beta, IL-6, and TNF-alpha in blood mononuclear cells. J Appl Physiol. 1985;89(4):1499-504.

14. de Mello VD, Kolehmainen M, Schwab U, Mager U, Laaksonen DE, Pulkkinen $\mathrm{L}$, et al. Effect of weight loss on cytokine messenger RNA expression in peripheral blood mononuclear cells of obese subjects with the metabolic syndrome. Metabolism. 2008;57(2):192-9.

15. Sheu WH, Chang TM, Lee WJ, Ou HC, Wu CM, Tseng LN, et al. Effect of weight loss on proinflammatory state of mononuclear cells in obese women. Obesity (Silver Spring). 2008;16(5):1033-8. 
16. Bresciani G, Gonzalez-Gallego J, da Cruz IB, de Paz JA, Cuevas MJ. The Ala16Val MnSOD gene polymorphism modulates oxidative response to exercise. Clin Biochem. 2013;46(4-5):335-40

17. American College of Sports Medicine. ACSM's guidelines for exercise testing and prescription. 9th ed. Philadelphia: Lippincott Williams \& Wilkins; 2013.

18. Karvonen J, Vuorimaa T. Heart rate and exercise intensity during sports activities. Practical application Sports Med. 1988;5(5):303-11.

19. Bruce RA, Kusumi F, Hosmer D. Maximal oxygen intake and nomographic assessment of functional aerobic impairment in cardiovascular disease. Am Heart J. 1973;85(4):546-62.

20. Hanasand M, Omdal R, Norheim KB, Goransson LG, Brede C, Jonsson G. Improved detection of advanced oxidation protein products in plasma. Clin Chim Acta. 2012:413(9-10):901-6.

21. Ohkawa H, Ohishi N, Yagi K. Assay for lipid peroxides in animal tissues by thiobarbituric acid reaction. Anal Biochem. 1979;95(2):351-8.

22. Tatsch E, Bochi GV, Pereira Rda S, Kober H, Agertt VA, de Campos MM, et al. A simple and inexpensive automated technique for measurement of serum nitrite/nitrate. Clin Biochem. 2011;44(4):348-50.

23. Ellman GL. Tissue sulfhydryl groups. Arch Biochem Biophys. 1959;82(1):70-7.

24. Livak KJ, Schmittgen TD. Analysis of relative gene expression data using real-time quantitative PCR and the 2(-Delta Delta C(T)) Method. Methods. 2001;25(4):402-8.

25. Scagliusi FB, Ferriolli E, Pfrimer K, Laureano C, Cunha CS, Gualano B, et al. Underreporting of energy intake in Brazilian women varies according to dietary assessment: a cross-sectional study using doubly labeled water. J Am Diet Assoc. 2008;108(12):2031-40.

26. Fantuzzi G. Adipose tissue, adipokines, and inflammation. J Allergy Clin Immunol. 2005:115(5):911-9. quiz 20.

27. Gillen JB, Percival ME, Ludzki A, Tarnopolsky MA, Gibala MJ. Interval training in the fed or fasted state improves body composition and muscle oxidative capacity in overweight women. Obesity (Silver Spring). 2013;21(11):2249-55.

28. Gleeson M, Bishop NC, Stensel DJ, Lindley MR, Mastana SS, Nimmo MA. The anti-inflammatory effects of exercise: mechanisms and implications for the prevention and treatment of disease. Nat Rev Immunol. 2011;11(9):607-15.

29. Sakurai T, Izawa T, Kizaki T, Ogasawara JE, Shirato K, Imaizumi K, et al. Exercise training decreases expression of inflammation-related adipokines through reduction of oxidative stress in rat white adipose tissue. Biochem Biophys Res Commun. 2009;379(2):605-9.

30. Lei J, Vodovotz Y, Tzeng E, Billiar TR. Nitric oxide, a protective molecule in the cardiovascular system. Nitric Oxide. 2013;35:175-85.

31. Maeda S, Tanabe T, Otsuki T, Sugawara J, lemitsu M, Miyauchi T, et al. Moderate regular exercise increases basal production of nitric oxide in elderly women. Hypertens Res. 2004;27(12):947-53.

32. Ciolac EG, Bocchi EA, Bortolotto LA, Carvalho VO, Greve JM, Guimaraes GV. Effects of high-intensity aerobic interval training vs. moderate exercise on hemodynamic metabolic and neuro-humoral abnormalities of young normotensive women at high familial risk for hypertension. Hypertens Res. 2010;33(8):836-43.

33. Green DJ, Maiorana A, O'Driscoll G, Taylor R. Effect of exercise training on endothelium-derived nitric oxide function in humans. J Physiol. 2004;561(Pt 1):1-25.

34. Lumeng CN, Deyoung SM, Bodzin JL, Saltiel AR. Increased inflammatory properties of adipose tissue macrophages recruited during diet-induced obesity. Diabetes. 2007;56(1):16-23.

35. de Mello VD, Kolehmainen M, Pulkkinen L, Schwab U, Mager U, Laaksonen $D E$, et al. Downregulation of genes involved in NFkappaB activation in peripheral blood mononuclear cells after weight loss is associated with the improvement of insulin sensitivity in individuals with the metabolic syndrome: the GENOBIN study. Diabetologia. 2008;51(11):2060-7.

Submit your manuscript to a SpringerOpen ${ }^{\circ}$ journal and benefit from:

- Convenient online submission

- Rigorous peer review

- Immediate publication on acceptance

Open access: articles freely available online

- High visibility within the field

- Retaining the copyright to your article

Submit your next manuscript at $>$ springeropen.com 